\title{
Tribal Clans in Central India and Their Role in Conservation
}

The tradition of clans is apt to play an important role in the social set-up of any community, a clan being an aggregation of particular families having the same ancestors. However, there are some controversies regarding the origin of clans among the tribal grouping of Madhya Pradesh, a state in Central India. The important tribal communities of Madhya Pradesh are the Gond, Bheel, Kol, Auranb, Kamar, and Sahariya. The Sahariya tribal members inhabit mainly the four northern districts of Madhya Pradesh. The people of this tribe are mostly illiterate and very poor.

Collection of wild plants from forests is the main base of their economy. About 15 to 30 huts form a village-like unit called a 'Sahrana'. All of the huts of a 'Sahrana' are built facing towards the centre, where a place of worship is constructed. The head of the village is known as the Patel and settles all disputes. The staple food of Sahariyas is Sorghum (Sorghum vulgare), Maize (Zea mays), or sometimes wheat (Triticum spp.) which they take with salt or some leafy vegetables. Sahariyas believe in evil spirits and perform many rituals to appease them.

The Sahariyas comprise about 50 clans, which are related to their paternal family. A marriage between persons of the same clan is strictly prohibited; they are supposed to be brothers and sisters. During the present investigation, it was observed that certain clans of Sahariyas are named after certain plants which occur in the neighbouring forests; but it was found that the Sahariyas do not even touch the plant to which their clan's name belongs. Table I shows the names of some such clans, the related plants, the local names, and the manner in which conservation of the plants is effected.

The importance of the tradition of clans among Sahariyas in conservation of plants is evident and direct. Besides these clans based on plants, there are several clans which are related to animals. These clansmen do not eat the flesh of the related animals.

There are a number of popular stories or legends about the origin and naming of particular clans or sub-clans. Similar observations have been made among Munda tribal units of Bihar State (Gupta, 1981), where the clans are named after plants. The faith of early Man in the conservation of plants and other biological resources has led to
TABLE I

\begin{tabular}{|c|c|c|c|}
\hline Clan & Name of the plant & $\begin{array}{l}\text { Local } \\
\text { name }\end{array}$ & Taboo Conservation \\
\hline 1. Umariya & Ficus racemosa & Umar & $\begin{array}{l}\text { Worship the tree and } \\
\text { never cut it. }\end{array}$ \\
\hline $\begin{array}{l}\text { 2. Peepar } \\
\text { Barodiya }\end{array}$ & F. religiosa & Peepal & $\begin{array}{l}\text { Tag leaves on the fore- } \\
\text { head of bridegroom. }\end{array}$ \\
\hline 3. Dhanik & $\begin{array}{l}\text { Anogeissus } \\
\text { latifolia }\end{array}$ & Dho & Worship the tree. \\
\hline 4. Semariya & Salmalia indica & Semal & Worship the tree. \\
\hline 5. Samaria & Crotolaria juncea & San & $\begin{array}{l}\text { Do not sit on a cot } \\
\text { woven of its fibres. }\end{array}$ \\
\hline 6. Salaiya & Boswellia serrata & Salai & Worship the tree. \\
\hline 7. Jhilmiliya & Albizzia lebbeck & Siris & Worship the tree. \\
\hline
\end{tabular}

their survival in something like their former abundance in many areas on this Earth (Jain, 1986). Such information needs to be collected from many other tribal sources to show that this association of clan names and plants could be utilized widely for popularizing conservation.

The Author is grateful to Dr S.K. Jain, of the National Botanical Research Institute, Lucknow, for useful suggestions, and to the Head of the School in Botany, Jiwaji University, for facilities and encouragement.

\section{REFERENCES}

GUPTA, S.P. (1981). Folk-lore about plants with reference to Munda Culture. Pp. 199-207 in Glimpses of Indian Ethnobotany (Ed. S.K. Jain). Oxford \& IBH Publication Co., New Delhi, India: [not available for checking].

JAIN, S.K. (1986). Ethnobotany. Interdis. Sci. Rev., 11(3), pp. 28591, illustr.

AsHOK K. JAIN School of Studies in Botany. Jiwaji L'niversity

Gwalior

India.

\section{Guidance for Environmental Entrepreneurs}

A steam-powered aeroplane, glasshouse heating from farm wastes, and a revolutionary water-pump, are widely different ideas with one thing in common: they would be innovations that could bring great environmental benefits through their wide application. The Conservation Foundation, a UK-based organization providing a link between industry, commerce, and environmental interests, hears from many hopeful inventors of such innovations. Some simply want to report a successful product-launch and others want to enter for the Conservation Engineering category of the Europe-wide Ford Conservation Awards which are run by the Conservation Foundation. Most want-and need-help.

We have noticed through the course of such correspondence that, though the products or ideas varied, the wouldbe innovators shared many problems. Thus they lacked the funds and resources to undertake proper research and development, while tending to underestimate market resistance and overestimate the impact which publicity might have on their project. They also had similar attitudes, saying that, although they thought their idea had great commercial potential, they were mainly interested in the environmental benefits and were 'not really doing it for myself?

It was this concern for the environment and the desire to see their idea through at whatever cost, that led many innovators into difficulties. The environmental factor appeared to cloud their commercial judgement, and many persisted with their idea long after a conventional one would have been abandoned. Some apparently thought that the environmental spinoffs from their invention would oblige the Government to provide assistance or, if they only had some publicity, that a philanthropic investor could be found. In the Foundation's experience practically all these innovators have been proved tragically wrong.

The principles behind many of the innovations are sound, and some would indeed provide total or partial solutions to particular environmental problems. The Con- 